Check for updates

Department of Emergency Medicine, Harvard Medical School, Boston, MA USA

2 Department of Political Science, Texas Tech University, Lubbock, TX USA

Correspondence to: R N Salas rnsalas@mgh.harvard.edu

Cite this as: BMJ 2021;374:n2100 http://dx.doi.org/10.1136/bmj.n2100 Published: 27 August 2021

\section{Climate action for health and hope}

\author{
UN special report's findings cannot be ignored \\ Renee N Salas, ${ }^{1}$ Katharine Hayhoe ${ }^{2}$
}

The most serious type of heart attack, an ST elevation myocardial infarction (STEMI), is a life threatening emergency. Once health professionals sound the alarm, an interprofessional team immediately implements critical, time sensitive interventions to help the patient. Focused, oriented actions are the foundation for the evidence based hope in medicine-that intervention can prevent suffering and save lives.

Today, the world is reckoning with a diagnosis as dire as STEMI. Like too much plaque in an artery, decades of heat-trapping gas emissions from fossil fuel combustion and land use change have built up in the atmosphere, warming our planet and creating a health crisis. ${ }^{1}$ The sixth assessment report of the United Nations Intergovernmental Panel on Climate Change (IPCC) documents how a $1.1^{\circ} \mathrm{C}$ increase in global temperature is already fuelling record breaking heat waves, amplifying drought, intensifying wildfires, supercharging tropical cyclones, increasing extreme rainfall, and accelerating coastal flooding. ${ }^{1}$ The more the climate changes, the more frequent, stronger, and more damaging its extremes will become. $^{1-3}$

Humans' effect on climate was first discovered in the $1800 s,{ }^{4}$ and its risks were clearly presented to the US president in $1965 .{ }^{5}$ Our collective failure to respond in a timely manner has led to a bleak prognosis: a hazardous and even potentially fatal outcome for human populations globally. Some symptoms are already here, and others are inevitable because of emissions over the past century. Without aggressive treatment, the IPCC projects a temperature increase of $2^{\circ} \mathrm{C}$ by around mid-century, putting the Paris Agreement goals in jeopardy. But rapid and aggressive intervention can still limit warming to $1.5^{\circ} \mathrm{C}$ and avert the most dangerous consequences. ${ }^{1}$

\section{Emergency response}

Three lessons from clinical emergencies such as a STEMI can be applied to the climate crisis: first, make sure everyone knows the diagnosis and sound the alarm; second, catalyse time sensitive interventions; and third, work together to protect health and save life.

The problem is clear-fossil fuel combustion has caused a health crisis. ${ }^{26}$ Fine particulate air pollution from fossil fuel combustion leads to an estimated 8.7 million premature deaths annually, ${ }^{7}$ nearly double the current covid-19 death toll of 4.4 million. ${ }^{8}$ Climate change acts as a threat multiplier, magnifying the threats posed by existing health risks, food and water scarcity, and even socioeconomic, ethnic, and gender inequality. ${ }^{9}$
Climate change contributes to disease burdens across organ systems, both directly and indirectly, through geographically specific pathways, including intensifying extreme events (eg, wildfires and floods), enhancing the spread of vectorborne and waterborne diseases, decreasing air quality, reducing nutrition levels in crops, displacing populations, and disrupting health systems. ${ }^{6}$ Everyone is harmed to some degree, though these harms fall disproportionately on vulnerable and marginalised populations. ${ }^{6}$

One of the most important actions for health professionals, as trusted messengers, is to sound the alarm and put a human face on the risks of a $2^{\circ} \mathrm{C}$ rise in global temperature. Public opinion surveys show that only $43 \%$ of people in the US, for example, believe that climate change will harm them personally. ${ }^{10}$ Understanding the health harms of climate change makes the effects personal and the responses relevant. ${ }^{11}$

Once awareness is raised, action is needed. Many of the mitigations required for a rapid transition away from fossil fuels through sensible, equitable solutions are possible today. ${ }^{12}$ What we are primarily lacking is the motivation and political will to act. Cutting air pollution and carbon emissions has important near term health and equity benefits, including the reduction of deaths from air pollution. ${ }^{21314}$ The IPCC states that discernible differences in global temperature change that would reduce human suffering could be seen within 20 years. ${ }^{115}$

Just as every minute matters for a patient with a STEMI, every fraction of a degree of warming matters for human health. ${ }^{1516}$ Morbidity and mortality from heat, ground level ozone, and undernutrition are predicted to be much greater at $2^{\circ} \mathrm{C}$ of warming than at $1.5^{\circ} \mathrm{C} .{ }^{15}$ The higher threshold will also mean 61 million more people exposed to severe drought, 1.8 billion more people experiencing severe heatwaves at least once every five years, and twice the habitat loss for insects, plants, and vertebrates. ${ }^{17}$ This is why health professionals must view advocacy for climate mitigation, both inside and outside the healthcare sector, ${ }^{18}$ in the same way as cardiac catheterisation for STEMI.

A patient's life is saved by a team. Given the broad, interconnected nature of climate change, unprecedented collaborations within the health sector are essential, at both global and national levels. Collaborations must also expand beyond health, integrating the science of social movements ${ }^{19}$ and engaging social and behavioural scientists. ${ }^{20}$ Interventions and adaptations can reduce health harms when they are interdisciplinary, proactive, 
and prioritise iterative decision making in the face of uncertainty. ${ }^{15}$

The climate crisis is a health crisis and, just like a STEMI, has a narrow window for intervention. The health community has a responsibility to respond to this dire diagnosis, and it is time for clinicians to do what they do best: generate evidence based hope through timely action on climate change.

Competing interests: We have read and understood BMJ policy on declaration of interests and have no interests to declare.

Provenance and peer review: Commissioned; not externally peer reviewed.

1 Masson-Delmotte V, Zhai P, Pirani A, et al, eds. Summary for policymakers. AR6 climate change 2021: the physical science basis. Intergovernmental Panel on Climate Change, 2021.

https://www.ipcc.ch/report/ar6/wg1/\#SPM

2 Watts N, Amann M, Arnell N, etal. The 2020 report of the Lancet countdown on health and climate change: responding to converging crises. Lancet 2021;397:129-70. doi: 10.1016/S0140-6736(20)32290-X pmid: 33278353

3 Philip S, Kew SF, Oldenborgh GJ, etal. Rapid attribution analysis of the extraordinary heatwave on the Pacific Coast of the US and Canada June 2021. World Weather Attribution, 2021.

4 Archer D, Pierrehumbert R, eds. The warming papers: the scientific foundation for the climate change forecast. Wiley-Blackwell, 2011.

5 Restoring the quality of our environment. The report of the Environmental Pollution Panel President's Science Advisory Committee. White House, 1965.

6 Haines A, Ebi K. The imperative for climate action to protect health. N Engl J Med 2019;380:263-73. doi: 10.1056/NEJMra1807873 pmid: 30650330

7 Vohra K, Vodonos A, Schwartz J, Marais EA, Sulprizio MP, Mickley LJ. Global mortality from outdoor fine particle pollution generated by fossil fuel combustion: results from GEOS-Chem. Environ Res 2021;195:110754. doi: 10.1016/j.envres.2021.110754 pmid: 33577774

8 WHO. Coronavirus (covid-19) dashboard. 20 Aug 2021. https://covid19. who.int.

9 Salas RN, Solomon CG. The climate crisis-health and care delivery. N Engl J Med 2019;381:e13. doi: 10.1056/NEJMp1906035 pmid: 31433915

10 Marlon J, Howe P, Mildenberger M, Leiserowitz A. Wang X. Yale climate opinion maps 2020. 2 Sep 2020. https://climatecommunication.yale.edu/visualizations-data/ycom-us/

11 Morris BS, Chrysochou P, Christensen JD, etal. Stories vs. facts: triggering emotion and action-taking on climate change. Clim Change2019;154:19-36doi: 10.1007/s10584-019-02425-6.

12 Hawken P, ed. Drawdown: the most comprehensive plan every proposed to reverse global warming. Penguin Books, 2017.

13 Hamilton I, Kennard H, McGushin A, etal. The public health implications of the Paris Agreement: a modelling study. Lancet Planet Health 2021;5:e74-83. doi: 10.1016/S2542-5196(20)30249-7 pmid: 33581069

14 Sampedro J, Smith SJ, Arto I, etal. Health co-benefits and mitigation costs as per the Paris Agreement under different technological pathways for energy supply. Environ Int 2020;136:105513. doi: 10.1016/j.envint.2020.105513 pmid: 32006762

15 Ebi KBC, Ogden N, Paz S, etal. Burning embers: synthesis of the health risks of climate change. Environ Res Lett 2021;16:004042.

16 Ebi K, Hasegawa T, Hayes K, Monagham A, Paz S, Berry P. Health risks of warming of $1.5^{\circ} \mathrm{C}, 2$ ${ }^{\circ} \mathrm{C}$, and higher, above pre-industrial temperatures. Environ Res Lett 2018;13:063007.

17 Masson-Delmotte VP, Zhai H-O, Pörtner D, et al. Summary for policymakers. Special report: global warming of $1.5^{\circ} \mathrm{C}$. Intergovernmental Panel on Climate Change, 2018. https://www.ipcc.ch/sr15/chapter/spm/

18 Salas RN, Maibach E, Pencheon D, Watts N, Frumkin H. A pathway to net zero emissions for healthcare. BMJ 2020;371:m3785. doi: 10.1136/bmj.m3785 pmid: 33004403

19 Isgren E, Boda CS, Harnesk D, O'Byrne D. Science has much to offer social movements in the face of planetary emergencies. Nat Ecol Evol 2019:3:1498. doi: 10.1038/s41559-019-1024-x pmid: 31666735

20 Livingood WC, Allegrante JP, Airhihenbuwa CO, etal. Applied social and behavioral science to address complex health problems. Am J Prev Med 2011;41:525-31. doi: 10.1016/j.amepre.2011.07.021 pmid: 22011425 